\title{
Biologic and synthetic ligament reconstructions achieve better functional scores compared to osteosynthesis in the treatment of acute acromioclavicular joint dislocation
}

\author{
Maristella F. Saccomanno ${ }^{1}\left[{ }^{1} \cdot\right.$ Giuseppe Sircana $^{1} \cdot$ Valentina Cardona $^{1} \cdot$ Valeria Vismara $^{1} \cdot$ Alessandra Scaini $^{2}$. \\ Andrea G. Salvi ${ }^{2}$. Stefano Galli ${ }^{3} \cdot$ Giacomo Marchi $^{3} \cdot$ Giuseppe Milano ${ }^{2,3}$
}

Received: 31 March 2020 / Accepted: 6 August 2020

(c) European Society of Sports Traumatology, Knee Surgery, Arthroscopy (ESSKA) 2020

\begin{abstract}
Purpose To systematically review the outcomes of surgical treatments of acute acromioclavicular joint dislocation. Methods Studies were identified by electronic databases (Ovid, PubMed). All studies reporting functional and radiological outcomes of surgical treatments of acute acromioclavicular joint dislocations were included. Following data were extracted: authors and year, study design, level of evidence, number of patients, age, classification of acromioclavicular joint dislocation, time to surgery, surgical technique, follow-up, clinical and imaging outcomes, complications, and failures. Descriptive statistics was used, when a data pooling was not possible. Comparable outcomes were pooled to generate summary outcomes reported as frequency-weighted values. Quality appraisal was assessed through the MINORS checklist.

Results One hundred and thirty-three studies were included for a total of 4473 shoulders. Mean age of participants was 36.9 years. Mean follow-up was 42.06 months. Arthroscopy showed better ASES $(p<0.0001)$ and lower VAS pain score $(p=0.0249)$ compared to an open approach. Biologic and synthetic reconstructions demonstrated better results over osteosynthesis techniques. Biologic techniques showed overall better Constant $(p=0.0001)$ and DASH $(p=0.0215)$ scores, while synthetic reconstruction showed better UCLA score $(p=0.0001)$. Among suture buttons, triple button showed overall better results in Constant $(p=0.0001)$ and VAS $(p=0.0001)$ scores, while better results in DASH score $(p=0.0003)$ were achieved by 2 double button techniques. Overall, the level of evidence was low.

Conclusion Biological and synthetic reconstructions achieved better functional scores compared to osteosynthesis. Among suture buttons, the triple button showed better functional performance.
\end{abstract}

Level of evidence IV.

Keywords Acromioclavicular - Instability · Dislocation · Coracoclavicular ligament - Acromioclavicular ligament · Biologic $\cdot$ Synthetic $\cdot$ Tendon graft $\cdot$ Plate $\cdot$ Screws $\cdot$ Reconstruction

\section{Introduction}

Acromioclavicular (AC) joint dislocation is one of the most common traumatic injuries of the shoulder girdle, accounting for up to $12 \%$ of all injuries at this site [27]. AC joint dislocations mainly occur in young active men, especially

Electronic supplementary material The online version of this article (https://doi.org/10.1007/s00167-020-06217-9) contains supplementary material, which is available to authorized users.

Maristella F. Saccomanno

maristellasaccomanno@hotmail.it

Extended author information available on the last page of the article athletes involved in contact sports, in their second decade of life [110]. Correct diagnosis and proper treatment strategy are paramount to achieve good functional results. General consensus supports nonoperative treatment in type-I and type-II injuries according to the Rockwood classification, whereas high-grade injuries, like type-IV and type-V dislocations, usually undergo surgical treatment. Management of type-III AC joint dislocation is still under debate and surgical treatment is recommended only in younger patients with high functional requirements or in chronic symptomatic cases [114].

Whenever a surgical treatment is recommended, literature is still lacking on the definition of acute setting in AC joint dislocation, even if it seems that the earlier the surgery, the 
easier it is to obtain an accurate reduction and a better functional outcome [132].

Focusing on surgery, more than 100 surgical techniques have been described in the last decades, in both open and arthroscopic approaches, ranging from anatomic ligament reconstructions to osteosynthesis with plate and screws. Up to date, none of those techniques has demonstrated to be superior to the others [56]. Moreover, recent systematic reviews included both acute and chronic cases together, without making a distinction on results, further complicating the issue [53, 100].

The purpose of the present study was to systematically review the outcomes of surgical treatments of $\mathrm{AC}$ joint dislocation in an acute setting. The hypothesis of the study was that biologic AC joint reconstruction would result in better postoperative outcomes.

\section{Materials and methods}

A systematic review was conducted following the Preferred Reporting Items for Systematic Reviews and Meta-Analyses (PRISMA) guidelines [101].

\section{Literature search}

Studies were identified by searching major electronic databases (Ovid, PubMed). There were no restrictions on the date of publication or the language. The search was applied to MEDLINE through Ovid and then adapted for PubMed. All databases were examined from their inception up to March 03, 2020. Full search strategies are available in Appendix 1 in Supplementary material.

All studies reporting functional and radiological outcomes as well as revision rates after surgical treatment of acute $\mathrm{AC}$ joint dislocation were included (level of evidence I-IV). Both open and arthroscopic approaches were included. Studies comparing surgical versus conservative treatment as well as studies including chronic or revision cases were also included, with only the data from the primary acute surgical cases included in the analysis. If separate data could not be extracted, studies were excluded. Similarly, studies reporting outcomes of patients with associated shoulder pathologies, whose data were not separable from the rest of the study population, were also excluded. Animal studies, biomechanical studies, case reports, technical notes, review articles, expert opinions, and editorial pieces were excluded.

Two authors independently selected eligible studies from title and abstract. Subsequently, they analyzed the full text to confirm the inclusion in the study. Additionally, all references within included studies were cross-referenced for potential inclusion if omitted from the initial search.
Titles of journals, names of authors, or supporting institutions were not masked at any stage. No attempt was made to contact trialists regarding trial methodology and findings. Disagreements at any stage of the review process were resolved by consensus or third-party adjudication by the senior author.

\section{Data extraction and analysis}

The following data were then extracted: authors, year of publication, study design (prospective or retrospective), level of evidence (LOE), number of shoulders, patients' age, type of dislocation (according to Rockwood classification) time elapsed from injury to surgery, surgical approach (open or arthroscopic), surgical technique, length of follow-up, functional and subjective outcomes, loss of reduction, revision, and complications. Data were extracted by one investigator and cross-checked by another investigator.

Although all functional outcomes were reported in the data extraction form, only the most commonly reported scores were used for data analysis.

\section{Quality appraisal}

The methodological assessment of included studies was performed by two authors independently, by evaluating the potential risk of bias, both in comparative and in noncomparative studies, using the MINORS checklist [131]. The index includes 12 items, 4 of which dedicated only to comparative studies. Each item was scored 0 if not reported, 1 when reported but inadequate, and 2 when reported and adequate. The ideal score was 16 for non-comparative studies and 24 for comparative studies. Studies with a MINORS score $\leq 12$ and $\leq 20$ for non-comparative and comparative studies, respectively, were considered at high risk of bias.

\section{Statistical analysis}

Descriptive statistics was applied when data pooling was not possible. Comparable outcome data from individual studies were pooled to generate summary outcomes reported as frequency-weighted values (weighted mean and standard deviation). A number of shoulders in individual studies were used to determine the weight of reported outcomes and used to calculate the weighted values. Between-group differences for continuous variables were analyzed with Student's t test. Statistical significance was set at $p<0.05$. Statistical analysis was performed using GraphPad Prism 8 (GraphPad Software, San Diego, CA, USA). 


\section{Results}

\section{Study selection}

The electronic search resulted in 495 entries. After removing the duplicates, 371 studies remained. Of these, 191 were excluded based on their abstract and 47 additional studies were excluded based on the full-text article. One hundred and thirty-three $[1,2,4,5,7-10,12-15,17-23$, $25,29,30,32-41,43-46,49-52,54-61,64-67,69-73$, 75-82, 86-95, 97-99, 102-109, 111, 113, 117, 118, 120, $122-130,133,135,137-139,143,144,146-156,158$, $160-162,165-167,170-177]$ were finally included in the review (Fig. 1).

\section{Study characteristics}

Included studies reported data on 4473 shoulders. Mean age of participants was $36.9 \pm 5.17$ years (range, 15-84 years). One thousand six-hundred and fifty shoulders suffered from a Rockwood type-III dislocation, 420 shoulders a type-IV dislocation, and 1614 shoulders a type-V dislocation. Patients underwent surgery within 1 week from dislocation in 20 studies [4, 41, 43, 49, 51, 56, $57,75,76,78,81,82,91,138,148,151,152,156,160$, 176], 2 weeks in 52 studies [5, 7, 9, 10, 15, 19, 21, 30, 34-36, 44, 46, 58-60, 67, 70, 71, 87-90, 94, 97, 98, 105, $106,108,111,122,125-127,129,135,139,144,147$, $149,153,155,158,161,162,165,166,170-172,174$, 177], 3 weeks in 31 studies [2, 8, 12, 17, 20, 23, 25, 29, $33,37,50,54,61,65,66,72,77,79,95,99,109,118$, $123,128,130,133,143,150,155,167,175], 4$ weeks in 13 studies [1, 14, 38, 39, 55, 64, 73, 93, 107, 120, 124, $137,146], 6$ weeks in six studies $[22,92,102,103,117$, 173], and 6 months in one study [104]. Time from injury to surgery was not reported in ten studies $[13,18,32,40$, $52,69,80,86,113,154]$. The mean length of follow-up was $42.1 \pm 32.9$ months (range, $4-247$ months).

Two studies [14, 93] reported different results of the same population of patients, as stated in the Methods section. Different data were collected, but patients were considered only once.

According to the LOE, only nine studies were level I $[1,14,30,43,91,93,105,106,173]$ and five studies were level II [5, 65, 69, 129, 135].

Surgical techniques are summarized in Table 1.

Loss of reduction was reported on X-rays in 116 studies $[2,4,7,10,12-15,17-23,25,29,30,32-41,43,45,46$, 49-52, 54-61, 64-67, 69-73, 75-77, 86-88, 90-92, 94, 95, 97, 98, 102-104, 106-109, 111, 117, 118, 122-130, $133,135,137-139,143,144,146-154,156,158,160-162$,
165-167, 170-177], computed tomography (CT) was used in one study [78], magnetic resonance (MR) in one study [89], and clinical evaluation was used in two studies [79, 80], while in 13 studies $[1,5,8,9,44,81,82,93,99,105$, $113,120,155]$, it was not reported. Main definitions were summarized in Table 2.

Most commonly reported functional scores were: Constant score [26] in 94 studies, Visual Analogic Scale (VAS) for pain in 47 studies, Disabilities of the Arm, Shoulder and Hand (DASH) score [62] in 24 studies, University of California, Los Angeles (UCLA) shoulder rating scale [42] in 24 studies, and American Shoulder and Elbow Surgeons (ASES) society standardized shoulder assessment form [115] in 20 studies. Full list of clinical scores is reported in Table 3.

Single studies characteristics and outcomes are reported in detail in Appendix 2 in Supplementary material.

\section{Surgical approach comparison: open vs arthroscopic}

Main characteristics of studies based on surgical approach are reported in Table 4. One study [81] reported the results of open and arthroscopic techniques without providing separate data, which, therefore, was not included in the analyses. Functional outcomes of open and arthroscopic procedures are reported in Table 5. Statistically significant differences were found in VAS $(p=0.0249)$ and $\operatorname{ASES}(p=0.0001)$ score, favoring arthroscopic techniques.

\section{Biologic reconstruction vs synthetic reconstruction vs osteosynthesis}

Main characteristics of different surgical techniques are summarized in Table 6. Clinical outcomes are reported in Table 7. Biologic and synthetic techniques demonstrated better results in all analyzed outcomes over osteosynthesis techniques. Biologic techniques showed overall better results in Constant $(p=0.0001)$ and DASH $(p=0.0215)$ score, while synthetic techniques scored better results in UCLA ( $p=0.0001)$. No differences could be found between the biologic and synthetic group for VAS and ASES scores.

Pairwise comparisons of single techniques were attempted, but the paucity of studies analyzing the same technique, the consequent small number of patients, and the different outcomes considered prevented us from performing subgroup analysis of different surgical techniques except for the comparison between double and triple buttons.

\section{Double button vs triple button}

Main characteristics of studies reporting button techniques are summarized in Table 8 . Studies reporting button 

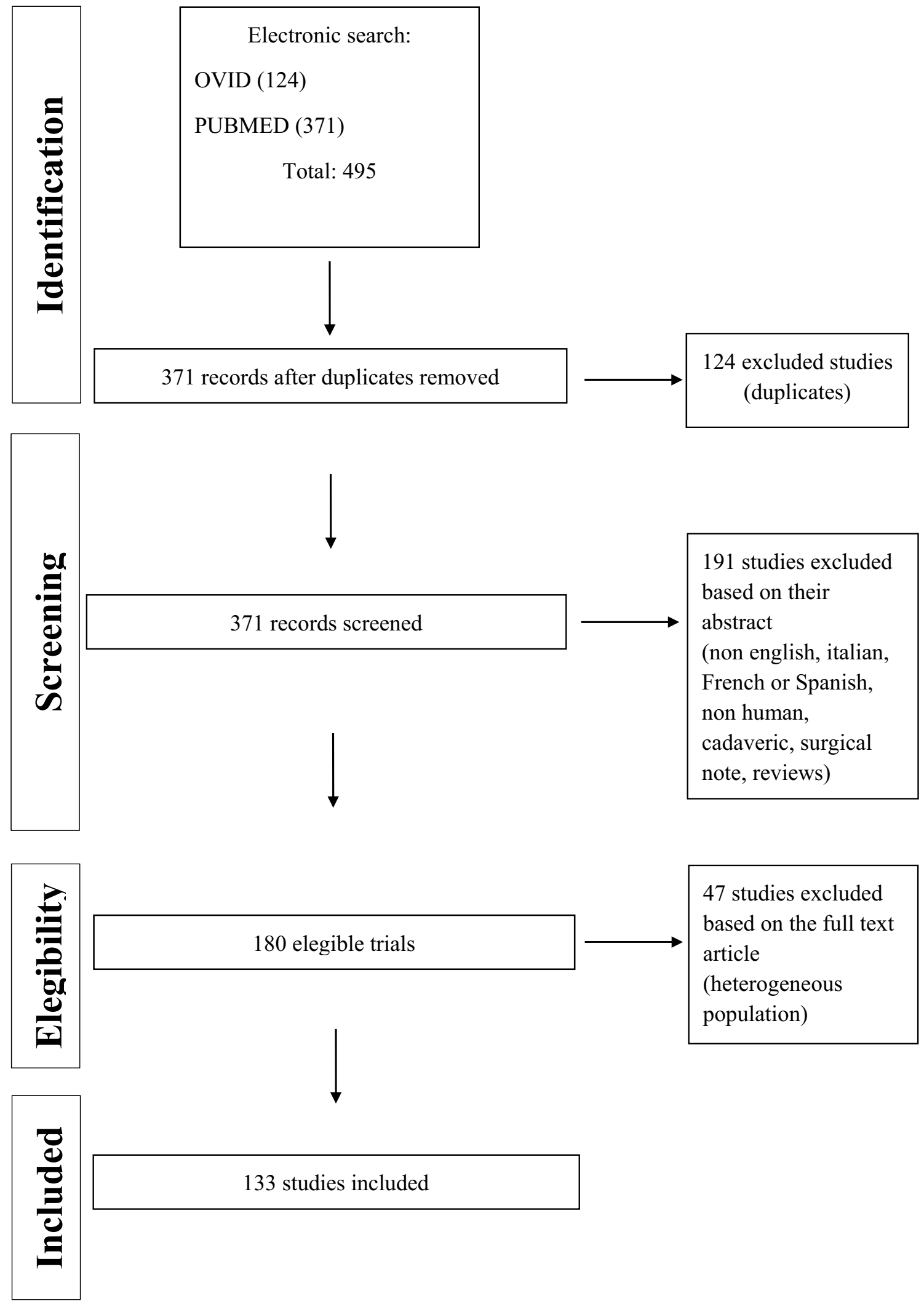

Fig. 1 Study selection based on PRISMA flowchart 
Table 1 Surgical techniques

\begin{tabular}{|c|c|c|}
\hline Biologic & Synthetic & Internal fixation \\
\hline Autograft CC reconstruction $[22,76,174]$ & $\begin{array}{l}\text { Double-button }[1,2,7,9,20,25,30,34,35, \\
\text { 40, 44-46, 52, 59, 60, 64, 67, 71, 87, 89, 91, } \\
\text { 98, 102, 107, 111, 118, 124, 125, 127, 133, } \\
137,138,144,148,155,156,170]\end{array}$ & $\begin{array}{l}\text { Hook plate }[9,14,49,58,61,70,81,93,98, \\
109,113,144,175,177]\end{array}$ \\
\hline Autograft AC reconstruction [51] & $\begin{array}{l}\text { Double-button and AC reconstruction [77, } \\
82,106]\end{array}$ & $\begin{array}{l}\text { Hook plate augmented with } \mathrm{AC} \text { repair }[19,38 \text {, } \\
173]\end{array}$ \\
\hline $\begin{array}{l}\text { Autograft CC reconstruction augmented with } \\
\text { K-wires [94] }\end{array}$ & Double-button augmented with pins [21] & Hook plate augmented with CC repair [105] \\
\hline $\begin{array}{l}\text { Autograft CC reconstruction augmented with } \\
\text { synthetic ligaments [143] }\end{array}$ & $\begin{array}{r}\text { Two double buttons }[60,69,97,105,107, \\
108,120,123,135,138,150,170,176]\end{array}$ & $\begin{array}{l}\text { Hook plate augmented with } \mathrm{AC} \text { and } \mathrm{CC} \text { repair } \\
{[19,32,160]}\end{array}$ \\
\hline $\begin{array}{l}\text { Allograft CC and AC reconstruction [77, 104, } \\
\text { 160] }\end{array}$ & $\begin{array}{l}\text { Two double buttons and } \mathrm{AC} \text { reconstruction } \\
{[56,97,171]}\end{array}$ & $\begin{array}{l}\text { Hook plate augmented with biologic recon- } \\
\text { struction }[99,158,173]\end{array}$ \\
\hline Modified Weaver-Dunn $[55,165,167]$ & Triple buttons $[12,15,44,91,126,166]$ & AC plate fixation [86] \\
\hline Modified Cadenat [17] & $\begin{array}{l}\text { Synthetic ligament reconstruction }[50,57,66 \text {, } \\
92,95,147,149,152,175]\end{array}$ & Bosworth screw $[5,30,139]$ \\
\hline Cadenat augmented with K-wires [37] & $\begin{array}{l}\text { Synthetic ligament reconstruction augmented } \\
\text { with K-wires [154] }\end{array}$ & $\begin{array}{l}\text { Bosworth screw augmented with ligament } \\
\text { repair }[4,18,90]\end{array}$ \\
\hline Cadenat augmented with suture anchors [128] & Synthetic tape reconstruction $[33,61,73]$ & $\begin{array}{l}\text { Bosworth screw augmented with temporary } \\
\text { K-wire }[129,177]\end{array}$ \\
\hline Dewar-Barrington [130] & Synthetic CC cerclage $[36,54,107]$ & CC wire cerclage $[39,49,172]$ \\
\hline $\begin{array}{l}\text { Dewar-Barrington augmented with K-wires } \\
\text { [162] }\end{array}$ & $\begin{array}{l}\text { Synthetic CC cerclage and AC reconstruction } \\
{[41,72,80,122]}\end{array}$ & AC screw fixation $[43,153]$ \\
\hline \multirow[t]{6}{*}{$\begin{array}{l}\text { Coraco-acromial ligament transfer augmented } \\
\text { with K-wires [103] }\end{array}$} & $\begin{array}{l}\text { Synthetic CC cerclage augmented with } \\
\text { K-wires }[8,94,117,151,155]\end{array}$ & K-wire fixation $[60,153]$ \\
\hline & $\begin{array}{l}\text { Suture anchor CC reconstruction }[23,29,44, \\
78,107,146]\end{array}$ & K-wire fixation with CC repair $[18,60]$ \\
\hline & & K-wire fixation with AC repair $[43,65,88]$ \\
\hline & & $\begin{array}{l}\text { K-wire fixation with } \mathrm{AC} \text { and } \mathrm{CC} \text { repair }[10,13 \text {, } \\
79,80]\end{array}$ \\
\hline & & Tension band fixation $[10,75]$ \\
\hline & & Knowles pin and CC cerclage [161] \\
\hline
\end{tabular}

$C C$ coracoclavicular, $A C$ acromioclavicular

techniques associated with $\mathrm{AC}$ reconstruction and augments were excluded from this analysis.

Functional outcomes are reported in Table 9. Triple button showed overall better results in Constant $(p=0.0001)$ and VAS $(p=0.0001)$ scores, while better results in DASH score $(p=0.0003)$ were achieved by 2 double buttons techniques. Double and triple button demonstrated better results in ASES $(p=0.0003)$ and UCLA $(p=0.0001)$ score over two double-button reconstruction.

\section{Risk of bias within studies}

The methodological quality of the included studies was low. The results of the MINORS checklist are reported in Appendix 3 in Supplementary material.

Eighty-two non-comparative studies $[2,4,7,8,12,15$, $17,20,22,23,25,29,32,33,36-41,45,46,50-52,54$, $55,57,58,64,66,67,72,73,75,76,82,86-90,95,97,99$, $102,103,111,113,117,118,120,122-124,126-128,130$,
$133,137,139,143,146-154,158,161,162,165-167,171$, $172,174,176]$ were at high risk of bias and only six [56, $70,71,78,92,104]$ were at low risk of bias; 34 comparative studies $[5,10,13,18,19,21,34,35,43,44,49,59,60$, 69, 77, 79-81, 91, 93, 94, 98, 106-109, 125, 144, 155, 156, $160,170,173,175]$ were at high risk of bias, while only 11 $[1,9,14,30,61,65,105,129,134,138,177]$ were at low risk of bias.

\section{Discussion}

Main findings of the present review showed that an open approach to the AC joint is still the most common adopted option. However, arthroscopy definitely presented some advantages in terms of lower VAS pain score and, somehow, in functional performance, at least when evaluated through the ASES score. Moreover, the percentage of postoperative OA was lower if an arthroscopic approach was used. 
Table 2 Main definitions of "reduction"

Definition

Vertical distance between the inferior border of the clavicle and the tip of the coracoid:

Anatomic: $<2 \mathrm{~mm}$

Slight loss: $2-4 \mathrm{~mm}$

Partial loss: $4-8 \mathrm{~mm}$

Complete loss: $>8 \mathrm{~mm}$

Vertical distance between the highest point of the clavicle and the acromion:

Anatomic: $<2 \mathrm{~mm}$

Slight loss: $2-4 \mathrm{~mm}$

Partial loss: 4-8 mm

Complete loss: $>8 \mathrm{~mm}$

Vertical distance between the inferior border of the clavicle and the acromion:

Minimal displacement: $<2 \mathrm{~mm}$

Mild displacement: 2-4 mm

Moderate displacement: 4-6 mm

Marked displacement: $>6 \mathrm{~mm}$

Translation measured on the AP width of the clavicle:

Slight loss: $<50 \%$

Obvious loss or dislocation: $>50 \%$

Side-to-side difference:

Anatomic: no difference

Partial loss: less than the width of the clavicle

Complete loss: more than the width of the clavicle

Translation measured on the AP width of the clavicle:

Anatomic: no displacement

Subluxation: $>50 \%$

Dislocation: $>100 \%$

Side-to-side difference measured on the height of the acromion:

Anatomic: no displacement

Subluxated: $<50 \%$

Dislocated: $>50 \%$

Superior translation of the clavicle in relation to the acromion:

$0 \%$ displacement

$25 \%$ displacement

$50 \%$ displacement

75\% displacement

$100 \%$ displacement

Side-to-side difference in CC distance:

Mild loss: 0-50\%

Subluxation: $50-100 \%$

Redislocation: $>100 \%$

Side-to-side difference in CC distance:

Slight loss: $25-90 \%$

Complete loss: $>90 \%$

Side-to-side difference:

Reduced: symmetric

Not reduced: not symmetric

Upward translation of the clavicle:

Recurrent subluxation: $<1 \mathrm{~cm}$

Complete redislocation: $>1 \mathrm{~cm}$

AC joint step-off:

Mild subluxation: $<25 \%$

Moderate subluxation: $25-50 \%$

Severe subluxation: $>50 \%$

Increase in CC length by $25-100 \%$ compared to the contralateral side

Increase in $\mathrm{CC}$ distance $>50 \%$

Side-to-side difference in CC distance $\geq 2 \mathrm{~mm}$

Side-to-side difference in $\mathrm{CC}$ distance $\geq 3 \mathrm{~mm}$

Side-to-side difference in CC distance $\geq 5 \mathrm{~mm}$
Radiologic evaluation

Radiograph [23, 92, 142, 147, 158]

Radiograph [21, 86, 149]

Radiograph [174]

Radiograph [91, 98, 138, 153]

Radiograph [4, 33, 162, 167]

Radiograph [153]

Radiograph [13, 72, 108, 109]

Radiograph [94]

MRI [89]

Radiograph [61, 127, 127, 128]

Radiograph [23]

Radiograph [14]

Radiograph [35]

Radiograph [66]

Radiograph [15, 173]

Radiograph [71, 126]

Radiograph [125]

Radiograph [151]

Radiograph [156] 
Table 2 (continued)

\begin{tabular}{ll}
\hline Definition & Radiologic evaluation \\
\hline CC distance increase from the initial postoperative radiographs $\geq 2 \mathrm{~mm}$ & Radiograph [20] \\
CC distance increase from the initial postoperative radiographs $\geq 5 \mathrm{~mm}$ & Radiograph [77] \\
$50 \%$ difference in CC distance between the two shoulders & Radiograph [30] \\
Translation in the vertical plane greater than 50\% of the clavicle shaft width & Radiograph [17, 41, 118, 124] \\
Translation in the vertical plane greater than 100\% of the clavicle shaft width & Radiograph [59] \\
Posterior displacement: a clavicle not in line with the acromion & TC [102] \\
25\% increase in CC distance from the immediate postoperative radiograph & Radiograph [22] \\
CC distance $>100 \%$ compared to the contralateral side & Radiograph [54] \\
CC distance ratio with contralateral shoulder $>150 \%$ & Radiograph [19] \\
Partial vertical and horizontal failure: & Radiograph [56, 97] \\
CC distance $>25 \%$ & Radiograph [64] \\
Total horizontal failure: & Radiograph [75] \\
Posterior translation of the clavicle of more than a clavicle width & \\
CC distance ratio $>1.2$ & AC distance $>20$ mm
\end{tabular}

$A C$ acromioclavicular, $A P$ antero-posterior, $C C$ coracoclavicular

On the contrary, the open approach showed lower rate of loss of reduction and revisions. Looking deeper into surgical techniques, regardless of the approach, biologic and synthetic reconstructions showed better functional scores compared to osteosynthesis techniques. Particularly, biologic reconstructions showed the best Constant and DASH score overall, thus partially accepting the hypothesis of the study. Osteosynthesis techniques showed the lowest rate of loss of reduction, but the highest percentage of postoperative OA. Surprisingly, although the percentages were not high, biologic reconstructions showed the highest revision rate among the three groups. Taking into account that biologic reconstructions showed at the same time the best Constant score, but also the highest revision rate, a subgroup analysis, e.g., between anatomic and non-anatomic techniques, could have surely been helpful for a better understanding of the results. Unfortunately, available data did not allow any further comparison. On the contrary, a deeper investigation into the results of synthetic reconstructions was possible. According to the current available literature, suture buttons seemed the favored choice in the acute setting. Interestingly, triple button showed the best functional performance in terms of pain reduction and Constant score. Triple button also displayed a very low rate of postoperative OA and revisions, even if it showed the highest percentage of loss of reduction compared to double buttons.

Arthroscopic techniques are growing in volume and efficiency. Main advantages are related to: first, the opportunity to check the status of the glenohumeral joint and the subacromial space to rule out, and eventually treat, concomitant pathologies; second, ease of access to the undersurface of the base of the coracoid, which it is surely the trickiest part when an anatomic coracoclavicular (CC) ligament reconstruction with tendon graft, suture, or tape is attempted. However, as the approach has never been regarded as a real issue in AC joint surgery and considering the ease of access to the joint, probably, a room for an open approach will always stay.

Definition of "acute" setting still remains a controversial issue. As recent reviews [53, 100], focused on clinical and imaging outcomes after AC joint reconstruction, included both acute and chronic cases, it cannot be denied that the two settings exhibit different biological characteristics, and then, surgical management should be dissimilar. According to the papers included in the present review, the acute setting mostly ranges from 3 days $[43,56,81,152,160,176]$, up to 6 weeks [22, 92, 102, 103, 117, 173] after trauma. Recently, some authors clearly stated that 3 weeks can set the separation line to achieve better results, maximizing the biological support from injured and surrounding tissues [47, 96]. Therefore, if 3 weeks can be considered "the golden hour", 3-6 weeks can also be regarded as the gray zone or the subacute phase, before shifting into the chronic setting [47].

Anyhow, the aim of surgery should always be the restoration of normal anatomy and kinematic of the joint. Therefore, it is not a surprise that biological and synthetic reconstruction achieved better functional results compared to osteosynthesis devices. The previous reviews [3, 159] compared suture buttons and hook plate, as they are the most common devices in synthetic and osteosynthesis group, respectively. The authors showed that suture buttons resulted in better functional scores and lower VAS pain score. However, while Arirachakaran et al. [3] found a higher loss of reduction in the suture button group, no 
Table 3 Reported functional outcome scores

\begin{tabular}{|c|c|c|}
\hline Score & $N$ studies & References \\
\hline Constant score [26] & 94 & $\begin{array}{l}{[1,2,7-9,12,14,15,17,18,20,23,25,30,32,34,36,38,40} \\
\quad 41,44-46,49,50,54,56,58,64,65,67,69-72,75,76,78-80, \\
82,86,87,89,91,92,94,95,98,99,102-104,108,109,111, \\
113,117,118,120,122-124,126-129,133,135,137,138,144, \\
147-151,153-156,158,160-162,166,170-177]\end{array}$ \\
\hline Visual Analogic Scale (VAS) for pain & 47 & $\begin{array}{l}{[1,2,7,12,17-19,35,50,58,60,61,64,72,75,80-82,89,91} \\
\quad 92,94,107-109,113,122,126,133,138,144,147,148,150 \\
153,155,156,162,166,170-177]\end{array}$ \\
\hline Disabilities of the Arm, Shoulder and Hand (DASH) score [62] & 24 & $\begin{array}{l}{[2,4,7,12,14,30,35,46,51,54,72,73,106-109,122,144,147,} \\
\quad 148,151,153,154,176]\end{array}$ \\
\hline $\begin{array}{l}\text { University of California, Los Angeles (UCLA) shoulder rating } \\
\text { scale [42] }\end{array}$ & 24 & $\begin{array}{l}{[4,12,19,21-23,34,41,45,52,60,61,65,70,71,107,137,143,} \\
\quad 144,147,149,154,160,162]\end{array}$ \\
\hline $\begin{array}{l}\text { American Shoulder and Elbow Surgeons (ASES) society stand- } \\
\text { ardized shoulder assessment form [115] }\end{array}$ & 20 & $\begin{array}{l}{[4,19,21,22,34,41,60,77,79-81,102,122,125,126,137,144,} \\
\quad 147,149,173]\end{array}$ \\
\hline Simple Shoulder Test (SST) [85] & 11 & {$[44,60,65,104,137,138,144,147,150,151,153]$} \\
\hline Subjective Shoulder Value (SSV) [48] & 11 & {$[21,35,54,56,58,64,69,75,97,123,124]$} \\
\hline AcromioClavicular Joint Instability (ACJI) score [123] & 9 & {$[8,15,34,56,69,97,98,123,124]$} \\
\hline Taft score $[142]$ & 8 & {$[56,69,97,98,118,123,124,135]$} \\
\hline Oxford Shoulder Score (OSS) [31] & 6 & {$[30,44,55,61,106,155]$} \\
\hline Quick-DASH [6] & 6 & {$[58,64,75,89,120,156]$} \\
\hline 36-item Short-Form health survey (SF-36) [164] & 6 & {$[93,107-109,147,150]$} \\
\hline Imatani score [63] & 3 & {$[13,139,165]$} \\
\hline Shoulder Pain And Disability Index (SPADI) [116] & 3 & {$[58,79,80]$} \\
\hline $\begin{array}{l}\text { German Extra Short Musculoskeletal Function Assessment } \\
\text { Questionnaire (XSMFA-D) [169] }\end{array}$ & 2 & {$[79,80]$} \\
\hline Numeric Analog Scale (NAS) & 2 & {$[105,135]$} \\
\hline Tegner activity scale [145] & 2 & {$[106,120]$} \\
\hline Athletic Shoulder Outcome Scoring System (ASOSS) [134] & 1 & {$[105]$} \\
\hline $\begin{array}{l}\text { Japan Shoulder Society Acromioclavicular Joint Function } \\
\text { Assessment (JSS-ACJ) score }\end{array}$ & 1 & {$[57]$} \\
\hline Korean shoulder scoring system (KSS) [141] & 1 & {$[125]$} \\
\hline Larsen score [74] & 1 & {$[65]$} \\
\hline L'Insalata score [84] & 1 & {$[38]$} \\
\hline Musculoskeletal Function Assessment (MFA) [140] & 1 & {$[67]$} \\
\hline Patte score [112] & 1 & {$[37]$} \\
\hline Rowe score [119] & 1 & {$[104]$} \\
\hline Shoulder Sport Activity Score (SSAS) [134] & 1 & {$[105]$} \\
\hline Single Assessment Numeric Evaluation (SANE) [168] & 1 & [77] \\
\hline $\begin{array}{l}\text { Subjective Patient Outcome for Return to Sports (SPORTS) } \\
\text { score [11] }\end{array}$ & 1 & {$[44]$} \\
\hline 12-item Short-Form health survey (SF-12) [163] & 1 & [106] \\
\hline Western Ontario Shoulder Instability Index (WOSI) [68] & 1 & {$[60]$} \\
\hline
\end{tabular}

differences could be noticed by Wang et al. [159]. The results of the present study confirmed the findings of Arirachakaran et al. [3]. Although the loss of reduction is somehow related to failure, the results of the present study not only showed a high variability in the definition of loss of reduction, but also showed that loss of reduction and functional outcomes did not correlate most of the times. On the contrary, the higher rate of OA noticed by the present study in the osteosynthesis group could probably well explain the worse results at the VAS pain score.

Costic et al. [28] stated that the anatomic reconstruction of CC ligaments more closely approximates joint kinematics than non-anatomic surgical techniques, and the incorporation of the biologic graft might improve the overall mechanical properties once healing occurred. Nonetheless, 
Table 4 Main characteristics of included studies based on the surgical approach: open vs arthroscopy

\begin{tabular}{|c|c|c|}
\hline & Open techniques & Arthroscopic techniques \\
\hline Number of studies & $\begin{array}{l}102[1,2,4,5,7-10,12-15,17-19,21-23,29,30,32,34 \\
36-39,41,43,44,49,50,54,55,58-61,65-67,70-73, \\
75-77,79-81,86,88,90-95,98,99,102-107,109 \\
113,117,118,122,124,128-130,135,137-139,144, \\
146-149,151-155,158,160-162,165-167,171-173 \\
175-177]\end{array}$ & $\begin{array}{l}36[1,9,20,25,33,35,40,44-46,52,56,57,64,69,82,87 \\
89,97,105,107,108,111,120,123,125-127,133,135, \\
143,150,155,156,170,174]\end{array}$ \\
\hline Number of patients & 3490 & 937 \\
\hline Loss of reduction & $482 / 2925(16.5 \%)$ & $158 / 663(23.8 \%)$ \\
\hline Revision & $70 / 1910(3.7 \%)$ & $39 / 623(6.3 \%)$ \\
\hline Osteoarthritis & $271 / 1806(15 \%)$ & $20 / 240(8.3 \%)$ \\
\hline Complications & $\begin{array}{l}\text { CC calcifications (373) } \\
\text { Undefined heterotopic ossification (78) } \\
\text { Infection (74) } \\
\text { Hardware mobilization (72) } \\
\text { Persistence of pain (63) } \\
\text { Lateral clavicle osteolysis (50) } \\
\text { Osteolysis around the hardware (47) } \\
\text { Acromial erosion (33) } \\
\text { Hardware breakage (25) } \\
\text { Keloids (21) } \\
\text { Clavicle erosion (17) } \\
\text { ROM reduction (10) } \\
\text { AC calcifications (7) } \\
\text { Impingement syndrome (7) } \\
\text { Coracoid fracture (6) } \\
\text { Shoulder stiffness (6) } \\
\text { Clavicle fracture (5) } \\
\text { Scapular dyskinesis (2) } \\
\text { Transient plexus lesion (1) } \\
\text { Basilic vein thrombosis (1) } \\
\text { Olecranon bursitis (1) }\end{array}$ & $\begin{array}{l}\text { CC calcifications (99) } \\
\text { Hardware migration (68) } \\
\text { Persistence of pain (14) } \\
\text { Tunnel widening (8) } \\
\text { Scapular dyskinesis (8) } \\
\text { Clavicle erosion (7) } \\
\text { Infection (6) } \\
\text { Keloids (4) } \\
\text { Shoulder stiffness (3) } \\
\text { Hardware breakage (2) } \\
\text { Coracoid fracture (1) } \\
\text { Ulnar nerve pain (1) } \\
\text { Clavicle fracture (1) } \\
\text { Coracoid fracture (1) } \\
\text { Osteolysis around the hardware (1) }\end{array}$ \\
\hline
\end{tabular}

$A C$ acromioclavicular; $C C$ coracoclavicular

synthetic reconstructions remain the most common choice at least in the acute setting.

The double-button technique was first introduced by Struhl [136], thus mimicking the conoid ligament. One year later, the triple button was first introduced by Lim et al. [83] to provide an anatomic reconstruction of $\mathrm{CC}$ ligament complex. A recent biomechanical study [24] proved the triple button to be stronger and more stable than the double button, since the absence of the reconstructed "trapezoid ligament" increased the posterior displacement of the distal clavicle during the forward flexion. From a clinical standpoint, the results of the present study confirmed the superiority of the triple button over the double button at least for the most commonly used scores (Constant and VAS score). Since the double button was mostly used by performing only two tunnels (one in the clavicle and one in the coracoid), available data did not allow a further analysis comparing the triple button and the double button combined with a second hole in the distal clavicle tied by simple suture to recreate the trapezoid ligament, as originally described by Struhl et al. [136].
In 2010, Salzmann et al. [121] introduced the use of two double buttons. The technique was supported by a previous biomechanical study [157], which showed that two double buttons resulted with equal or even higher forces than native ligaments. The present review could not show better clinical outcomes for the two double buttons over double and triple buttons, except for the DASH score.

Finally, although biomechanics [16] and clinical findings [123] warranted the reconstruction or at least the repair of the AC ligament complex to manage horizontal instability, only a few studies $[15,33,41,50,51,56,61,72,73,80,82$, $94,97,103,104,106,122,149,160,171]$ took care of it in both biologic and synthetic groups.

The present study presents some limitations and potential biases. The methodological quality of the included studies was low, possibly reducing the strength of evidence: only nine level I studies were included, while most included papers were level IV studies. Only 45 of the included studies were comparative in nature. Most of the included studies were retrospective case series. Despite the considerable number of patients included, many different surgical 
Table 5 Clinical outcomes of open vs arthroscopic approach

\begin{tabular}{|c|c|c|c|c|c|}
\hline \multirow[t]{2}{*}{ Functional scores } & \multicolumn{2}{|l|}{ Open techniques } & \multicolumn{2}{|l|}{ Arthroscopic techniques } & \multirow[t]{2}{*}{$P$ values } \\
\hline & Included studies & Weighted mean \pm SD & Included studies & Weighted mean \pm SD & \\
\hline Constant & $\begin{array}{l}71[1,2,7-9,12,14,15,17,18 \\
23,30,32,34,36,38,41,44 \\
49,50,54,58,65,67,70-72 \\
75,76,79,80,86,91,92,94 \\
95,98,99,102-104,109,113 \\
117,118,122,124,128,129 \\
135,137,138,144,147-149 \\
151,153-155,158,160-162 \\
166,171-173,175-177]\end{array}$ & $91.8 \pm 5$ & $\begin{array}{c}28[1,9,20,25,40,44-46,56 \\
64,69,78,82,87,89,108, \\
111,120,123,126,127,133, \\
135,150,155,156,170,174]\end{array}$ & $91.7 \pm 3.9$ & ns \\
\hline VAS & $\begin{array}{l}36[1,2,7,12,17-19,50,58,60 \\
61,72,75,80,81,91,92,94 \\
107,109,113,122,138,144 \\
147,148,153,155,162,166 \\
171-173,175-177]\end{array}$ & $12.2 \pm 11.7$ & $\begin{array}{l}14[1,35,64,82,89,107,108 \\
126,133,150,155,156,170 \\
174]\end{array}$ & $10.7 \pm 6.2$ & 0.0249 \\
\hline DASH & $\begin{array}{c}21[2,4,7,12,14,30,51,54,72 \\
73,106,107,109,122,144 \\
147,148,151,153,154,176]\end{array}$ & $6.5 \pm 9.1$ & $4[35,46,107,108]$ & $7 \pm 2.3$ & ns \\
\hline ASES & $\begin{array}{l}18[4,19,21,22,34,41,60,77 \\
\quad 79-81,102,122,137,144,147 \\
149,173]\end{array}$ & $76.2 \pm 28$ & $2[125,126]$ & $91.2 \pm 5.4$ & 0.0001 \\
\hline UCLA & $\begin{array}{l}21[4,12,19,21-23,34,41,60 \\
\quad 61,65,70,71,107,137,144 \\
147,149,154,160,162]\end{array}$ & $31.5 \pm 2.7$ & $4[45,52,107,143]$ & $31.6 \pm 2.4$ & ns \\
\hline
\end{tabular}

approaches and techniques have been included in the analysis, that could not be easily grouped and compared. Furthermore, the authors used different outcome measurements. Particularly, very few studies used AC joint-specific scores, thus reducing the possibility to highlight meaningful clinical differences. Moreover, different definitions of loss of reduction were provided. All these differences increased heterogeneity and hindered the pooling and comparison of data, thus impairing the external validity of our study. The scarce quality of the obtained evidence advocates the need for devising new high-quality studies that can clarify the subject.

Finally, from a clinical standpoint, results of the present review strongly recommend favoring anatomic reconstructions over osteosynthesis techniques in the treatment of acute $\mathrm{AC}$ joint dislocations.

\section{Conclusion}

Surgical treatment of acute high-grade (type-III-V) AC joint dislocations produces good clinical results. Based on the available data, biological and synthetic reconstructions achieved better functional scores compared to osteosynthesis. Synthetic reconstruction techniques represent the most common option in the acute setting. Particularly, triple button displayed a better constant and lower VAS pain scores, compared to double buttons. 
Table 6 Main characteristics of included studies based on surgical technique

\begin{tabular}{|c|c|c|c|}
\hline & Biologic & Synthetic & Internal fixation \\
\hline Number of studies & $\begin{array}{l}18[17,22,37,51,55,76,77,94,103 \\
104,128,130,143,160,162,165, \\
167,174]\end{array}$ & $\begin{array}{l}83[1,2,7-9,12,15,20,21,23,25,29, \\
30,33-36,40,41,44-46,50,52,54, \\
56,57,59-61,64,66,67,69,71-73, \\
77,78,80,82,87,89,91,92,94,95, \\
97,98,102,105-108,111,118,120, \\
122-127,133,135,137,138,144, \\
146-152,154-156,166,170,171, \\
175,176]\end{array}$ & $\begin{array}{l}45[4,5,9,10,13,14,18,19,30,32,38, \\
39,43,49,58-61,65,70,75,79-81, \\
86,88,90,93,98,99,105,109,113, \\
129,135,139,144,153,158,160,161, \\
172,173,175,177]\end{array}$ \\
\hline Number of patients & 486 & 2,528 & 1,459 \\
\hline Loss of reduction & $67 / 447(15 \%)$ & $446 / 2,006(22.2 \%)$ & $139 / 1140(12.2 \%)$ \\
\hline Revisions & $16 / 134(11.9 \%)$ & $74 / 1711(4.3 \%)$ & $19 / 723(2.6 \%)$ \\
\hline Osteoarthritis & $12 / 311(3.9 \%)$ & $108 / 990(10.9 \%)$ & $168 / 780(21.5 \%)$ \\
\hline Complications & $\begin{array}{l}\text { CC calcifications (57) } \\
\text { Infection (25) } \\
\text { Keloids (11) } \\
\text { Hardware mobilization (6) } \\
\text { Hardware breakage (5) } \\
\text { Coracoid fracture (4) } \\
\text { Clavicle fracture (4) } \\
\text { Persistence of pain (3) } \\
\text { Tunnel widening (2) } \\
\text { Olecranon bursitis (1) } \\
\text { Clavicle erosion (1) }\end{array}$ & $\begin{array}{l}\text { CC calcifications (312) } \\
\text { Hardware migration (74) } \\
\text { Osteolysis around the Hardware (51) } \\
\text { Undefined heterotopic Ossifications } \\
\quad(49) \text { infection (31) } \\
\text { Distal clavicle osteolysis (26) } \\
\text { Persistence of pain (20) } \\
\text { Hardware breakage (16) } \\
\text { Keloids (15) } \\
\text { Scapular dyskinesis (8) } \\
\text { Tunnel widening (6) } \\
\text { Shoulder stiffness (6) } \\
\text { Coracoid fracture (4) } \\
\text { Clavicle fracture (2) } \\
\text { Ulnar nerve pain (1) } \\
\text { Transient plexus lesion (1) } \\
\text { Basilic vein thrombosis (1) }\end{array}$ & $\begin{array}{l}\text { CC calcifications (110) } \\
\text { Hardware mobilization (58) } \\
\text { Distal clavicle osteolysis (49) } \\
\text { Undefined heterotopic ossifications (36) } \\
\text { Persistence of pain (33) } \\
\text { Acromial erosions (32) } \\
\text { Infection (24) } \\
\text { Hardware breakage (21) } \\
\text { Keloids (11) } \\
\text { AC calcifications (7) } \\
\text { Aesthetic deformity (7) } \\
\text { Impingement syndrome (7) } \\
\text { Shoulder stiffness (3) } \\
\text { Acromion and distal clavicle sclerosis } \\
\text { (3) } \\
\text { Scapular dyskinesis (2) } \\
\text { Clavicular fracture (1) }\end{array}$ \\
\hline
\end{tabular}

$A C$ acromioclavicular, $C C$ coracoclavicular 


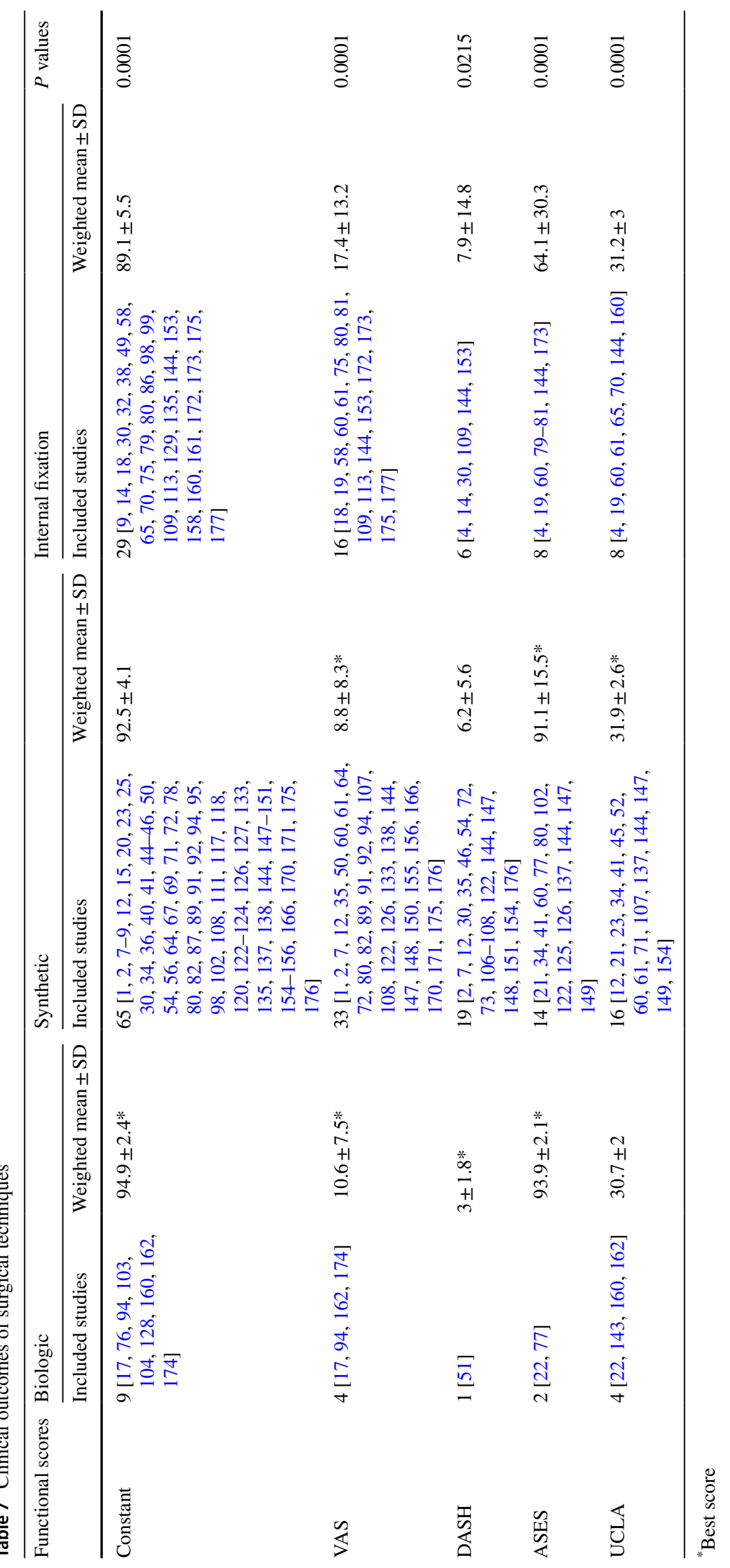


Table 8 Main characteristics of studies reporting button techniques

\begin{tabular}{lllc}
\hline & Double button & Triple button & Two double buttons \\
\hline Number of studies & $34[1,2,7,9,20,25,30,34,35,40,44-46,52,59,60,64,67,71$, & $5[12,44,91,126,166]$ & $12[60,69,105,107,108$, \\
& $87,89,98,102,107,118,124,125,127,133,138,148,155,156$, & $120,123,135,138,150$, \\
& $170]$ & 152 & $170,176]$ \\
Number of patients & 893 & $39 / 129(30.2 \%)$ & 318 \\
Loss of reduction & $102 / 657(15.5 \%)$ & $3 / 152(2 \%)$ & $44 / 208(21.2 \%)$ \\
Revision & $42 / 618(6.8 \%)$ & $4 / 105(3.8 \%)$ & $2 / 190(1.1 \%)$ \\
Osteoarthritis & $26 / 267(9.7 \%)$ & $9 / 64(14.1 \%)$ \\
\hline
\end{tabular}

Table 9 Clinical outcomes of double vs triple vs two-double buttons

\begin{tabular}{|c|c|c|c|c|c|c|c|}
\hline \multirow[t]{2}{*}{ Functional scores } & \multicolumn{2}{|l|}{ Double Button } & \multicolumn{2}{|l|}{ Triple Button } & \multicolumn{2}{|l|}{2 Double Buttons } & \multirow[t]{2}{*}{$P$ values } \\
\hline & Included studies & $\begin{array}{l}\text { Weighted } \\
\text { mean } \pm \text { SD }\end{array}$ & Included studies & $\begin{array}{l}\text { Weighted } \\
\text { mean } \pm \text { SD }\end{array}$ & Included studies & $\begin{array}{l}\text { Weighted } \\
\text { mean } \pm \text { SD }\end{array}$ & \\
\hline Constant & $\begin{array}{l}27[1,2,7,9,20 \\
25,30,34,40, \\
45,46,64,67 \\
71,87,89,98 \\
102,118,124, \\
127,133,138, \\
148,155,156, \\
170]\end{array}$ & $92 \pm 4.3$ & $\begin{array}{c}5[12,44,91, \\
126,166]\end{array}$ & $94.1 \pm 1.5^{*}$ & $\begin{array}{r}9[69,108,120 \\
123,135,138 \\
150,170,176]\end{array}$ & $93.3 \pm 1.3$ & 0.0001 \\
\hline VAS & $\begin{array}{c}14[1,2,7,35, \\
60,64,89,107, \\
133,138,148, \\
155,156,170]\end{array}$ & $11.3 \pm 9.9$ & $\begin{array}{l}4[12,91,126, \\
166]\end{array}$ & $5.5 \pm 3.8^{*}$ & $\begin{array}{l}7[60,107,108, \\
138,150,170 \\
176]\end{array}$ & $10.6 \pm 12.6$ & 0.0001 \\
\hline DASH & $\begin{array}{c}7[2,7,30,35, \\
46,107,148]\end{array}$ & $6.6 \pm 5.3$ & $1[12]$ & $9.1 \pm 14.3$ & $3[107,108,176]$ & $2.5 \pm 2.9^{*}$ & 0.0003 \\
\hline ASES & $\begin{array}{l}4[34,60,102, \\
125]\end{array}$ & $94.4 \pm 6.9 *$ & $1[126]$ & $95.7 \pm 3.6^{*}$ & $1[60]$ & $84.2 \pm 23.1$ & 0.0003 \\
\hline UCLA & $\begin{array}{l}6[34,45,52,60 \\
\quad 71,107]\end{array}$ & $32.4 \pm 1.7 *$ & $1[12]$ & $31 \pm 4.9^{*}$ & $2[60,107]$ & $29.8 \pm 2.2$ & 0.0001 \\
\hline
\end{tabular}

*Best score

Funding None.

\section{Compliance with ethical standards}

Conflict of interest The authors declare that they have no conflict of interest.

Ethical approval This article does not contain any studies with human participants or animals performed by any of the authors.

\section{References}

1. Abdelrahman AA, Ibrahim A, Abdelghaffar K, Ghandour TM, Eldib D (2019) Open versus modified arthroscopic treatment of acute acromioclavicular dislocation using a single tight rope: randomized comparative study of clinical outcome and costeffectiveness. J Shoulder Elbow Surg 28:2090-2097
2. Acar MA, Güleç A, Erkoçak ÖF, Yılmaz G, Durgut F, Elmadă M (2015) Percutaneous double-button fixation method for treatment of acute type III acromioclavicular joint dislocation. Acta Orthop Traumatol Turc 49:241-248

3. Arirachakaran A, Boonard M, Piyapittayanun P, Kanchanatawan W, Chaijenkij K, Prommahachai A, Kongtharvonskul J (2017) Post-operative outcomes and complications of suspensory loop fixation device versus hook plate in acute unstable acromioclavicular joint dislocation: a systematic review and meta-analysis. J Orthop Traumatol 18:293-304

4. Assaghir YM (2011) Outcome of exact anatomic repair and coracoclavicular cortical lag screw in acute acromioclavicular dislocations. J Trauma 71:E50-54

5. Bannister GC, Wallace WA, Stableforth PG, Hutson MA (1989) The management of acute acromioclavicular dislocation. A randomised prospective controlled trial. J Bone Joint Surg Br 71:848-850

6. Beaton DE, Wright JG, Katz JN, Upper Extremity Collaborative Group (2005) Development of the QuickDASH: comparison of three item-reduction approaches. J Bone Joint Surg Am 87:1038-1046 
7. Beris A, Lykissas M, Kostas-Agnantis I, Vekris M, Mitsionis G, Korompilias A (2013) Management of acute acromioclavicular joint dislocation with a double-button fixation system. Injury 44:288-292

8. Bigoni M, Piatti M, Zanchi N, Gorla M, Gaddi D, Rigamonti L, Omeljaniuk RJ, Zatti G, Turati M (2019) Clinical effectiveness of surgical treatment with polyester tapes and temporary K-wires on complete acromioclavicular dislocation. Eur J Orthop Surg Traumatol 29:567-573

9. Bin Abd Razak HR, Yeo E-MN, Yeo W, Lie T-TD (2018) Shortterm outcomes of arthroscopic TightRope ${ }^{\circledR}$ fixation are better than hook plate fixation in acute unstable acromioclavicular joint dislocations. Eur J Orthop Surg Traumatol 28:869-875

10. Biz C, Berizzi A, Cappellari A, Crimì A, Tamburin S, Iacobellis C (2015) The treatment of acute Rockwood type III acromioclavicular joint dislocations by two different surgical techniques. Acta Biomed 86:251-259

11. Blonna D, Bellato E, Caranzano F, Bonasia DE, Marmotti A, Rossi R, Castoldi F (2014) Validity and reliability of the SPORTS score for shoulder instability. Joints 2:59-65

12. Breuer R, Unterrainer A, Komjati M, Tiefenboeck TM, Trieb K, Pirkl C (2019) Minimally Invasive AC Joint Reconstruction System (MINAR $®$ ) in modified triple-button technique for the treatment of acute AC joint dislocation. J Clin Med 8:1683

13. Calvo E, López-Franco M, Arribas IM (2006) Clinical and radiologic outcomes of surgical and conservative treatment of type III acromioclavicular joint injury. J Shoulder Elbow Surg 15:300-305

14. Canadian Orthopaedic Trauma Society (2015) Multicenter randomized clinical trial of nonoperative versus operative treatment of acute acromio-clavicular joint dislocation. J Orthop Trauma 29:479-487

15. Cano-Martínez JA, Nicolás-Serrano G, Bento-Gerard J, PicazoMarín F, Andrés-Grau J (2016) Acute high-grade acromioclavicular dislocations treated with triple button device (MINAR): preliminary results. Injury 47:2512-2519

16. Celik H, Chauhan A, Flores-Hernandez C, Dorthe E, Goodine T, D'Lima D, Hoenecke H (2020) Vertical and rotational stiffness of coracoclavicular ligament reconstruction: a biomechanical study of 3 different techniques. Arthroscopy 36:1264-1270

17. Cerciello S, Edwards TB, Morris BJ, Cerciello G, Walch G (2014) The treatment of type III acromioclavicular dislocations with a modified Cadenat procedure: surgical technique and mid-term results. Arch Orthop Trauma Surg 134:1501-1506

18. Cetinkaya E, Arıkan Y, Beng K, Mutlu H, Yalçınkaya M, Üzümcügil O (2017) Bosworth and modified Phemister techniques revisited. A comparison of intraarticular vs extraarticular fixation methods in the treatment of acute Rockwood type III acromioclavicular dislocations. Acta Orthop Traumatol Turc 51:455-458

19. Chang H-M, Hong C-K, Su W-R, Wang T-H, Chang C-W, Tai T-W (2019) Comparison of clavicular hook plate with and without coracoclavicular suture fixation for acute acromioclavicular joint dislocation. Acta Orthop Traumatol Turc 53:408-413

20. Chaudhary D, Jain V, Joshi D, Jain JK, Goyal A, Mehta N (2015) Arthroscopic fixation for acute acromioclavicular joint disruption using the TightRope device. J Orthop Surg (Hong Kong) 23:309-314

21. Cho C-H, Kim B-S, Kwon D-H (2016) Importance of additional temporary pin fixation combined coracoclavicular augmentation using a suture button device for acute acromioclavicular joint dislocation. Arch Orthop Trauma Surg 136:763-770

22. Choi NH, Lim SM, Lee SY, Lim TK (2017) Loss of reduction and complications of coracoclavicular ligament reconstruction with autogenous tendon graft in acute acromioclavicular dislocations. J Shoulder Elbow Surg 26:692-698
23. Choi S, Lee T-J, Kim M-K, Park JE, Kang H (2016) Midterm results of coracoclavicular stabilization with double augmentation for acute acromioclavicular dislocation. SpringerPlus $5: 1858$

24. Civan O, Atmaca H, Uğur L (2020) Biomechanical comparison of double versus triple button reconstruction techniques in patients with acromioclavicular joint dislocation. Int J Med Robot 16:e2057

25. Cohen G, Boyer P, Pujol N, Hamida Ferjani B, Massin P, Hardy P (2011) Endoscopically assisted reconstruction of acute acromioclavicular joint dislocation using a synthetic ligament. Outcomes at 12 months. Orthop Traumatol Surg Res 97:145-151

26. Constant CR, Murley AH (1987) A clinical method of functional assessment of the shoulder. Clin Orthop Relat Res 214:160-164

27. Cook JB, Krul KP (2018) Challenges in treating acromioclavicular separations: current concepts. J Am Acad Orthop Surg 26:669-677

28. Costic RS, Labriola JE, Rodosky MW, Debski RE (2004) Biomechanical rationale for development of anatomical reconstructions of coracoclavicular ligaments after complete acromioclavicular joint dislocations. Am J Sports Med 32:1929-1936

29. Dal Molin DC, Ribeiro FR, Filho RB, Filardi CS, Tenor AC, Stipp WN, Petros RSB (2012) Posterosuperior surgical access route for treatment of acromioclavicular dislocations: results from 84 surgical cases. Rev Bras Ortop 47:563-567

30. Darabos N, Vlahovic I, Gusic N, Darabos A, Bakota B, Miklic D (2015) Is AC TightRope fixation better than Bosworth screw fixation for minimally invasive operative treatment of Rockwood III AC joint injury? Injury 46(Suppl 6):S113-118

31. Dawson J, Fitzpatrick R, Carr A (1996) Questionnaire on the perceptions of patients about shoulder surgery. J Bone Joint Surg Br 78:593-600

32. De Baets T, Truijen J, Driesen R, Pittevils T (2004) The treatment of acromioclavicular joint dislocation Tossy grade III with a clavicle hook plate. Acta Orthop Belg 70:515-519

33. De Beer J, Schaer M, Latendresse K, Raniga S, Moor BK, Zumstein MA (2017) BiPOD arthroscopic acromioclavicular repair restores bidirectional stability. Orthopedics 40:e35-e43

34. De Carli A, Lanzetti RM, Ciompi A, Lupariello D, Rota P, Ferretti A (2015) Acromioclavicular third degree dislocation: surgical treatment in acute cases. J Orthop Surg 10:13

35. Defoort S, Verborgt O (2010) Functional and radiological outcome after arthroscopic and open acromioclavicular stabilization using a double-button fixation system. Acta Orthop Belg 76:585-591

36. Dimakopoulos P, Panagopoulos A, Syggelos SA, Panagiotopoulos E, Lambiris E (2006) Double-loop suture repair for acute acromioclavicular joint disruption. Am J Sports Med 34:1112-1119

37. Dumontier C, Sautet A, Man M, Apoil A (1995) Acromioclavicular dislocations: treatment by coracoacromial ligamentoplasty. J Shoulder Elbow Surg 4:130-134

38. Ejam S, Lind T, Falkenberg B (2008) Surgical treatment of acute and chronic acromioclavicular dislocation Tossy type III and V using the Hook plate. Acta Orthop Belg 74:441-445

39. Ejeskär A (1974) Coracoclavicular wiring for acromioclavicular joint dislocation. A ten year follow-up study. Acta Orthop Scand 45:652-661

40. El Sallakh SA (2012) Evaluation of arthroscopic stabilization of acute acromioclavicular joint dislocation using the TightRope system. Orthopedics 35:e18-22

41. El Shewy MT, El Azizi H (2011) Suture repair using loop technique in cases of acute complete acromioclavicular joint dislocation. J Orthop Traumatol 12:29-35 
42. Ellman H, Hanker G, Bayer M (1986) Repair of the rotator cuff. End-result study of factors influencing reconstruction. J Bone Joint Surg Am 68:1136-1144

43. Eskola A, Vainionpää S, Korkala S, Santavirta S, Grönblad M, Rokkanen P (1991) Four-year outcome of operative treatment of acute acromioclavicular dislocation. J Orthop Trauma 5:9-13

44. Faggiani M, Vasario GP, Mattei L, Calò MJ, Castoldi F (2016) Comparing mini-open and arthroscopic acromioclavicular joint repair: functional results and return to sport. Musculoskelet Surg 100:187-191

45. Fahmy FS, Fathi H, ElAttar M (2019) Clinical outcomes of arthroscopic assissted fixation of acute high grade acromioclavicular joint disruption. J Orthop 16:133-136

46. Flinkkilä TE, Ihanainen E (2014) Results of arthroscopy-assisted TightRope repair of acromioclavicular dislocations. Shoulder Elbow 6:18-22

47. Flint JH, Wade AM, Giuliani J, Rue J-P (2014) Defining the terms acute and chronic in orthopaedic sports injuries: a systematic review. Am J Sports Med 42:235-241

48. Fuchs B, Jost B, Gerber C (2000) Posterior-inferior capsular shift for the treatment of recurrent, voluntary posterior subluxation of the shoulder. J Bone Joint Surg Am 82:16-25

49. Gao Y-S, Zhang Y-L, Ai Z-S, Sun Y-Q, Zhang C-Q, Zhang W (2015) Transarticular fixation by hook plate versus coracoclavicular stabilization by single multistrand titanium cable for acute Rockwood grade- $\mathrm{V}$ acromioclavicular joint dislocation: a casecontrol study. BMC Musculoskelet Disord 16:360

50. Geraci A, Riccardi A, Monia Montagner I, Pilla D, Camarda L, D'Arienzo A, D'arienzo M (2019) Acromion clavicular joint reconstruction with LARS ligament in acute dislocation. Arch Bone Joint Surg 7:143-150

51. Gogna P, Mukhopadhyay R, Singh A, Singla R, Batra A, Magu NK, Nara R (2015) Mini incision acromio-clavicular joint reconstruction using palmaris longus tendon graft. Musculoskelet Surg 99:33-37

52. Gòmez Vieira LA, Visco A, Daneu Fernandes LF, Gòmez Cordero NG (2009) Arthroscopic treatment of acromioclavicular joint dislocation by tight rope technique (Arthrex(®)). Rev Bras Ortop 44:52-56

53. Gowd AK, Liu JN, Cabarcas BC, Cvetanovich GL, Garcia GH, Manderle BJ, Verma NN (2019) Current concepts in the operative management of acromioclavicular dislocations: a systematic review and meta-analysis of operative techniques. Am J Sports Med 47:2745-2758

54. Greiner S, Braunsdorf J, Perka C, Herrmann S, Scheffler S (2009) Mid to long-term results of open acromioclavicular-joint reconstruction using polydioxansulfate cerclage augmentation. Arch Orthop Trauma Surg 129:735-740

55. Gupta R, Sood M, Malhotra A, Masih GD, Khanna T, Raghav M (2018) Functional outcome of modified weaver dunn technique for acromioclavicular joint dislocation. Indian J Orthop $52: 418-422$

56. Hann C, Kraus N, Minkus M, Maziak N, Scheibel M (2018) Combined arthroscopically assisted coraco- and acromioclavicular stabilization of acute high-grade acromioclavicular joint separations. Knee Surg Sports Traumatol Arthrosc 26:212-220

57. Hashiguchi H, Iwashita S, Abe K, Sonoki K, Yoneda M, Takai S (2018) Arthroscopic coracoclavicular ligament reconstruction for acromioclavicular joint dislocation. J Nippon Med Sch $85: 166-171$

58. von Heideken J, Boström Windhamre $\mathrm{H}$, Une-Larsson V, Ekelund A (2013) Acute surgical treatment of acromioclavicular dislocation type $\mathrm{V}$ with a hook plate: superiority to late reconstruction. J Shoulder Elbow Surg 22:9-17
59. Horst K, Dienstknecht T, Andruszkow H, Gradl G, Kobbe P, Pape H-C (2013) Radiographic changes in the operative treatment of acute acromioclavicular joint dislocation-tight rope technique vs. K-wire fixation. Pol J Radiol 78:15-20

60. Horst K, Garving C, Thometzki T, Lichte P, Knobe M, Dienstknecht T, Hofman M, Pape H-C (2017) Comparative study on the treatment of Rockwood type III acute acromioclavicular dislocation: clinical results from the TightRope ${ }^{\circledR}$ technique vs. K-wire fixation. Orthop Traumatol Surg Res 103:171-176

61. Huang Y-C, Yang S-W, Chen C-Y, Lin K-C, Renn J-H (2018) Single coracoclavicular suture fixation with Mersilene tape versus hook plate in the treatment of acute type $\mathrm{V}$ acromioclavicular dislocation: a retrospective analysis. J Orthop Surg 13:110

62. Hudak PL, Amadio PC, Bombardier C (1996) Development of an upper extremity outcome measure: the DASH (disabilities of the arm, shoulder and hand) [corrected]. The Upper Extremity Collaborative Group (UECG). Am J Ind Med 29:602-608

63. Imatani RJ, Hanlon JJ, Cady GW (1975) Acute, complete acromioclavicular separation. J Bone Joint Surg Am 57:328-332

64. Issa S-P, Payan C, Le Hanneur M, Loriaut P, Boyer P (2018) Arthroscopically assisted reduction of acute acromioclavicular joint dislocation using a single double-button device: mediumterm clinical and radiological outcomes. Orthop Traumatol Surg Res 104:33-38

65. Joukainen A, Kröger H, Niemitukia L, Mäkelä EA, Väätäinen U (2014) Results of operative and nonoperative treatment of rockwood Types III and V acromioclavicular joint dislocation: a prospective, randomized trial with an 18- to 20-year follow-up. Orthop J Sports Med 2:2325967114560130

66. Kappakas GS, McMaster JH (1978) Repair of acromioclavicular separation using a dacron prosthesis graft. Clin Orthop Relat Res 131:247-251

67. Katsenis DL, Stamoulis D, Begkas D, Tsamados S (2015) Minimally invasive reconstruction of acute type IV and Type V acromioclavicular separations. Orthopedics 38:e324-330

68. Kirkley A, Griffin S, McLintock H, Ng L (1998) The development and evaluation of a disease-specific quality of life measurement tool for shoulder instability. The Western Ontario Shoulder Instability Index (WOSI). Am J Sports Med 26:764-772

69. Kraus N, Haas NP, Scheibel M, Gerhardt C (2013) Arthroscopically assisted stabilization of acute high-grade acromioclavicular joint separations in a coracoclavicular Double-TightRope technique: V-shaped versus parallel drill hole orientation. Arch Orthop Trauma Surg 133:1431-1440

70. Kumar N, Sharma V (2015) Hook plate fixation for acute acromioclavicular dislocations without coracoclavicular ligament reconstruction: a functional outcome study in military personnel. Strateg Trauma Limb Reconstr 10:79-85

71. Kurtoglu A, Sukur E, Cicekli O, Daldal I, Kochai A, Sen Z, Hali A (2020) Does the ZipTightTM effective to maintain reduction after the treatment of acute acromioclavicular joint dislocation? Medicine (Baltimore) 99:e19387

72. Lädermann A, Grosclaude M, Lübbeke A, Christofilopoulos P, Stern R, Rod T, Hoffmeyer P (2011) Acromioclavicular and coracoclavicular cerclage reconstruction for acute acromioclavicular joint dislocations. J Shoulder Elbow Surg 20:401-408

73. LaMartina JA, Lau BC, Miller L, Salesky MA, Feeley BT, Ma CB, Zhang AL (2018) Acute fixation of Type IV and V acromioclavicular separations: an internal splint technique. Orthop J Sports Med 6:2325967118783752

74. Larsen E, Bjerg-Nielsen A, Christensen P (1986) Conservative or surgical treatment of acromioclavicular dislocation. A prospective, controlled, randomized study. J Bone Joint Surg Am 68:552-555

75. Lateur G, Boudissa M, Rubens-Duval B, Mader R, Rouchy RC, Pailhé R, Saragaglia D (2016) Long-term outcomes of tension 
band wiring with a single K-wire in Rockwood type IV/V acute acromio-clavicular dislocations: 25 cases. Orthop Traumatol Surg Res 102:589-593

76. Law KY, Yung SH, Ho PY, Chang HT, Chan KM (2007) Coracoclavicular ligament reconstruction using a gracilis tendon graft for acute type-III acromioclavicular dislocation. J Orthop Surg (Hong Kong) 15:315-318

77. Lee BK, Jamgochian GC, Syed UAM, Getz CL, Dodson CC, Namdari S, Ramsey ML, Williams GR, Abboud JA, Lazarus MD (2019) Reconstruction of acute acromioclavicular (AC) Joint dislocations with or without Tendon Graft: a retrospective comparative study. Arch Bone Joint Surg 7:239-245

78. Lee S-J, Yoo Y-S, Kim Y-S, Jang S-W, Kim J, Kim S-J, Kim B-S, Jung K-H, Varshney A (2019) Arthroscopic coracoclavicular fixation using multiple low-profile devices in acute acromioclavicular joint dislocation. Arthroscopy 35:14-21

79. Leidel BA, Braunstein V, Kirchhoff C, Pilotto S, Mutschler W, Biberthaler P (2009) Consistency of long-term outcome of acute Rockwood grade III acromioclavicular joint separations after K-wire transfixation. J Trauma 66:1666-1671

80. Leidel BA, Braunstein V, Pilotto S, Mutschler W, Kirchhoff C (2009) Mid-term outcome comparing temporary K-wire fixation versus PDS augmentation of Rockwood grade III acromioclavicular joint separations. BMC Res Notes 2:84

81. Li G, Liu T, Shao X, Liu Z, Duan J, Akileh R, Cao S, Jin D (2018) Fifteen-degree clavicular hook plate achieves better clinical outcomes in the treatment of acromioclavicular joint dislocation. J Int Med Res 46:4547-4559

82. Li H, Wang C, Wang J, Wu K, Hang D (2013) Restoration of horizontal stability in complete acromioclavicular joint separations: surgical technique and preliminary results. Eur J Med Res $18: 42$

83. Lim YW (2008) Triple endobutton technique in acromioclavicular joint reduction and reconstruction. Ann Acad Med Singap 37:294-299

84. L'Insalata JC, Warren RF, Cohen SB, Altchek DW, Peterson MG (1997) A self-administered questionnaire for assessment of symptoms and function of the shoulder. J Bone Joint Surg Am 79:738-748

85. Lippitt S, Harryman D, Matsen F (1993) A practical tool for evaluating function: the simple shoulder test. Shoulder Balance Mobil Stab American Academy of Orthopaedic Surgeons, Rosemont, pp 501-518

86. Liu Q, Miao J, Lin B, Guo Z (2012) Clinical effect of acute complete acromioclavicular joint dislocation treated with micromovable and anatomical acromioclavicular plate. Int J Med Sci 9:725-729

87. Liu X, Huangfu X, Zhao J (2015) Arthroscopic treatment of acute acromioclavicular joint dislocation by coracoclavicular ligament augmentation. Knee Surg Sports Traumatol Arthrosc 23:1460-1466

88. Lizaur A, Marco L, Cebrian R (1994) Acute dislocation of the acromioclavicular joint. Traumatic anatomy and the importance of deltoid and trapezius. J Bone Joint Surg Br 76:602-606

89. Loriaut P, Casabianca L, Alkhaili J, Dallaudière B, Desportes E, Rousseau R, Massin P, Boyer P (2015) Arthroscopic treatment of acute acromioclavicular dislocations using a double button device: clinical and MRI results. Orthop Traumatol Surg Res 101:895-901

90. Lowe GP, Fogarty MJ (1977) Acute acromioclavicular joint dislocation: results of operative treatment with the Bosworth screw. Aust N Z J Surg 47:664-667

91. Lu D, Wang T, Chen H, Sun L-J (2016) A comparison of double Endobutton and triple Endobutton techniques for acute acromioclavicular joint dislocation. Orthop Traumatol Surg Res 102:891-895
92. Lu N, Zhu L, Ye T, Chen A, Jiang X, Zhang Z, Zhu Q, Guo Q, Yang D (2014) Evaluation of the coracoclavicular reconstruction using LARS artificial ligament in acute acromioclavicular joint dislocation. Knee Surg Sports Traumatol Arthrosc 22:2223-2227

93. Mah JM, Canadian Orthopaedic Trauma Society (COTS) (2017) General health status after nonoperative versus operative treatment for acute, complete acromioclavicular joint dislocation: results of a multicenter randomized clinical trial. J Orthop Trauma 31:485-490

94. Mardani-Kivi M, Mirbolook A, Salariyeh M, Hashemi-Motlagh K, Saheb-Ekhtiari K (2013) The comparison of Ethibond sutures and semitendinosus autograft in the surgical treatment of acromioclavicular dislocation. Acta Orthop Traumatol Turc 47:307-310

95. Mares O, Luneau S, Staquet V, Beltrand E, Bousquet P-J, Maynou C (2010) Acute grade III and IV acromioclavicular dislocations: outcomes and pitfalls of reconstruction procedures using a synthetic ligament. Orthop Traumatol Surg Res 96:721-726

96. Martetschläger F, Kraus N, Scheibel M, Streich J, Venjakob A, Maier D (2019) The diagnosis and treatment of acute dislocation of the acromioclavicular joint. Dtsch Arzteblatt Int 116:89-95

97. Maziak N, Audige L, Hann C, Minkus M, Scheibel M (2019) Factors predicting the outcome after arthroscopically assisted stabilization of acute high-grade acromioclavicular joint dislocations. Am J Sports Med 47:2670-2677

98. Metzlaff S, Rosslenbroich S, Forkel PH, Schliemann B, Arshad H, Raschke M, Petersen W (2016) Surgical treatment of acute acromioclavicular joint dislocations: hook plate versus minimally invasive reconstruction. Knee Surg Sports Traumatol Arthrosc 24:1972-1978

99. Mitev K, Zafiroski G, Mladenovski S, Nikolov L (2019) Surgical outcomes after fixation of acromioclavicular joint dislocation with hook plate and coracoacromial ligament transfer technique. Open Access Maced J Med Sci 7:1013-1015

100. Moatshe G, Kruckeberg BM, Chahla J, Godin JA, Cinque ME, Provencher MT, LaPrade RF (2018) Acromioclavicular and coracoclavicular ligament reconstruction for acromioclavicular joint instability: a systematic review of clinical and radiographic outcomes. Arthroscopy 34:1979-1995.e8

101. Moher D, Shamseer L, Clarke M, Ghersi D, Liberati A, Petticrew M, Shekelle P, Stewart LA, PRISMA-P Group (2015) Preferred reporting items for systematic review and meta-analysis protocols (PRISMA-P) 2015 statement. Syst Rev 4:1

102. Mori D, Yamashita F, Kizaki K, Funakoshi N, Mizuno Y, Kobayashi M (2017) Anatomic coracoclavicular ligament reconstruction for the treatment of acute acromioclavicular joint dislocation: minimum 10-year follow-up. JB JS Open Access 2:e0007

103. Moura DL, Reis E, Reis A, Ferreira J, Capelão M, Braz Cardoso J (2018) A combined technique for acromioclavicular reconstruction after acute dislocation - technical description and functional outcomes. Rev Bras Ortop 53:67-74

104. Muench LN, Kia C, Jerliu A, Murphy M, Berthold DP, Cote MP, Arciero RA, Mazzocca AD (2019) Functional and radiographic outcomes after anatomic coracoclavicular ligament reconstruction for Type III/V acromioclavicular joint injuries. Orthop J Sports Med 7:2325967119884539

105. Müller D, Reinig Y, Hoffmann R, Blank M, Welsch F, Schweigkofler U, Stein T (2018) Return to sport after acute acromioclavicular stabilization: a randomized control of double-suturebutton system versus clavicular hook plate compared to uninjured shoulder sport athletes. Knee Surg Sports Traumatol Arthrosc 26:3832-3847

106. Murray IR, Robinson PG, Goudie EB, Duckworth AD, Clark K, Robinson CM (2018) Open reduction and tunneled suspensory device fixation compared with nonoperative treatment for Type-III and Type-IV acromioclavicular joint dislocations: the 
ACORN prospective, randomized controlled trial. J Bone Joint Surg Am 100:1912-1918

107. Nascimento AT, Claudio GK (2016) Functional and radiological evaluation of acute acromioclavicular dislocation treated with anchors without eyelet: comparison with other techniques. Rev Bras Ortop 51:561-568

108. Natera Cisneros L, Sarasquete Reiriz J (2017) Unstable acromioclavicular joint injuries: Is there really a difference between surgical management in the acute or chronic setting? J Orthop $14: 10-18$

109. Natera-Cisneros L, Sarasquete-Reiriz J, Escolà-Benet A, Rodriguez-Miralles J (2016) Acute high-grade acromioclavicular joint injuries treatment: arthroscopic non-rigid coracoclavicular fixation provides better quality of life outcomes than hook plate ORIF. Orthop Traumatol Surg Res 102:31-39

110. Pallis M, Cameron KL, Svoboda SJ, Owens BD (2012) Epidemiology of acromioclavicular joint injury in young athletes. Am J Sports Med 40:2072-2077

111. Pan Z, Zhang H, Sun C, Qu L, Cui Y (2015) Arthroscopy-assisted reconstruction of coracoclavicular ligament by Endobutton fixation for treatment of acromioclavicular joint dislocation. Arch Orthop Trauma Surg 135:9-16

112. Patte D, Goutallier D (1988) Extensive anterior release in the painful shoulder caused by anterior impingement. Rev Chir Orthop Reparatrice Appar Mot 74:306-311

113. Pereira-Graterol E, Álvarez-Díaz P, Seijas R, Ares O, Cuscó X, Cugat R (2013) Treatment and evolution of grade III acromioclavicular dislocations in soccer players. Knee Surg Sports Traumatol Arthrosc 21:1633-1635

114. Phadke A, Bakti N, Bawale R, Singh B (2019) Current concepts in management of ACJ injuries. J Clin Orthop Relat Res Trauma 10:480-485

115. Richards RR, An KN, Bigliani LU, Friedman RJ, Gartsman GM, Gristina AG, Iannotti JP, Mow VC, Sidles JA, Zuckerman JD (1994) A standardized method for the assessment of shoulder function. J Shoulder Elbow Surg 3:347-352

116. Roach KE, Budiman-Mak E, Songsiridej N, Lertratanakul Y (1991) Development of a shoulder pain and disability index. Arthritis Care Res 4:143-149

117. Rolf O, Hann von Weyhern A, Ewers A, Boehm TD, Gohlke F (2008) Acromioclavicular dislocation Rockwood III-V: results of early versus delayed surgical treatment. Arch Orthop Trauma Surg 128:1153-1157

118. Rosslenbroich SB, Schliemann B, Schneider KN, Metzlaff SL, Koesters CA, Weimann A, Petersen W, Raschke MJ (2015) Minimally invasive coracoclavicular ligament reconstruction with a flip-button technique (MINAR): clinical and radiological midterm results. Am J Sports Med 43:1751-1757

119. Rowe CR, Patel D, Southmayd WW (1978) The Bankart procedure: a long-term end-result study. J Bone Joint Surg Am 60:1-16

120. Saier T, Plath JE, Beitzel K, Minzlaff P, Feucht JM, Reuter S, Martetschläger F, Imhoff AB, Aboalata M, Braun S (2016) Return-to-activity after anatomical reconstruction of acute highgrade acromioclavicular separation. BMC Musculoskelet Disord 17:145

121. Salzmann GM, Walz L, Buchmann S, Glabgly P, Venjakob A, Imhoff AB (2010) Arthroscopically assisted 2-bundle anatomical reduction of acute acromioclavicular joint separations. Am J Sports Med 38:1179-1187

122. Sandmann GH, Martetschläger F, Mey L, Kraus TM, Buchholz A, Ahrens P, Stöckle U, Freude T, Siebenlist S (2012) Reconstruction of displaced acromio-clavicular joint dislocations using a triple suture-cerclage: description of a safe and efficient surgical technique. Patient Saf Surg 6:25
123. Scheibel M, Dröschel S, Gerhardt C, Kraus N (2011) Arthroscopically assisted stabilization of acute high-grade acromioclavicular joint separations. Am J Sports Med 39:1507-1516

124. Schliemann B, Roßlenbroich SB, Schneider KN, Theisen C, Petersen W, Raschke MJ, Weimann A (2015) Why does minimally invasive coracoclavicular ligament reconstruction using a flip button repair technique fail? An analysis of risk factors and complications. Knee Surg Sports Traumatol Arthrosc 23:1419-1425

125. Seo J-B, Lee D-H, Kim K-B, Yoo J-S (2019) Coracoid clavicular tunnel angle is related with loss of reduction in a single-tunnel coracoclavicular fixation using a dog bone button in acute acromioclavicular joint dislocation. Knee Surg Sports Traumatol Arthrosc 27:3835-3843

126. Shin S-J, Jeon YS, Kim RG (2017) Arthroscopic-assisted coracoclavicular ligament reconstruction for acute acromioclavicular dislocation using 2 clavicular and 1 coracoid cortical fixation buttons with suture tapes. Arthroscopy 33:1458-1466

127. Shin S-J, Kim N-K (2015) Complications after arthroscopic coracoclavicular reconstruction using a single adjustable-loop-length suspensory fixation device in acute acromioclavicular joint dislocation. Arthroscopy 31:816-824

128. Shin S-J, Yun Y-H, Yoo JD (2009) Coracoclavicular ligament reconstruction for acromioclavicular dislocation using 2 suture anchors and coracoacromial ligament transfer. Am J Sports Med 37:346-351

129. Shui X, Chen S, Huang G, Kong J, Zhou C, Lin W (2018) Percutaneous minimally invasive repair of acromioclavicular joint dislocation using cannulated screws under ultrasonic vs. C-arm navigation: a prospective trial. Orthop Traumatol Surg Res 104:743-748

130. Skjeldal S, Lundblad R, Dullerud R (1988) Coracoid process transfer for acromioclavicular dislocation. Acta Orthop Scand 59:180-182

131. Slim K, Nini E, Forestier D, Kwiatkowski F, Panis Y, Chipponi J (2003) Methodological index for non-randomized studies (minors): development and validation of a new instrument. ANZ J Surg 73:712-716

132. Song T, Yan X, Ye T (2016) Comparison of the outcome of early and delayed surgical treatment of complete acromioclavicular joint dislocation. Knee Surg Sports Traumatol Arthrosc 24:1943-1950

133. Spoliti M, De Cupis M, Via AG, Oliva F (2014) All arthroscopic stabilization of acute acromioclavicular joint dislocation with fiberwire and endobutton system. Muscles Ligaments Tendons J 4:398-403

134. Stein T, Linke RD, Buckup J, Efe T, von Eisenhart-Rothe R, Hoffmann R, Jäger A, Welsch F (2011) Shoulder sport-specific impairments after arthroscopic Bankart repair: a prospective longitudinal assessment. Am J Sports Med 39:2404-2414

135. Stein T, Müller D, Blank M, Reinig Y, Saier T, Hoffmann R, Welsch F, Schweigkofler U (2018) Stabilization of acute highgrade acromioclavicular joint separation: a prospective assessment of the clavicular hook plate versus the double double-button suture procedure. Am J Sports Med 46:2725-2734

136. Struhl S (2007) Double endobutton technique for repair of complete acromioclavicular joint dislocations. Tech Shoulder Elb Surg 8:175-179

137. Struhl S, Wolfson TS (2015) Continuous loop double endobutton reconstruction for acromioclavicular joint dislocation. Am J Sports Med 43:2437-2444

138. Sun L-J, Lu D, Ma Y-F, Yu B (2019) Minimally invasive procedure of acute acromioclavicular joint dislocation: one suturebutton device versus two suture-button devices. Acta Orthop Belg 85:54-62 
139. Sundaram N, Patel DV, Porter DS (1992) Stabilization of acute acromioclavicular dislocation by a modified Bosworth technique: a long-term follow-up study. Injury 23:189-193

140. Swiontkowski MF, Engelberg R, Martin DP, Agel J (1999) Short musculoskeletal function assessment questionnaire: validity, reliability, and responsiveness. J Bone Joint Surg Am 81:1245-1260

141. Tae S-K, Rhee Y-G, Park T-S, Lee K-W, Park J-Y, Choi C-H, Koh S-H, Oh JH, Kim S-Y, Shin S-J (2009) The development and validation of an appraisal method for rotator cuff disorders: the Korean Shoulder Scoring System. J Shoulder Elbow Surg 18:689-696

142. Taft TN, Wilson FC, Oglesby JW (1987) Dislocation of the acromioclavicular joint. An end-result study. J Bone Joint Surg Am 69:1045-1051

143. Takase K, Yamamoto K (2016) Arthroscopic procedures and therapeutic results of anatomical reconstruction of the coracoclavicular ligaments for acromioclavicular Joint dislocation. Orthop Traumatol Surg Res 102:583-587

144. Taleb H, Afshar A, Shariyate MJ, Tabrizi A (2019) Comparison of short-term clinical outcomes of hook plate and continuous loop double endobutton fixations in acute acromioclavicular joint dislocation. Arch Bone Joint Surg 7:545-550

145. Tegner Y, Lysholm J (1985) Rating systems in the evaluation of knee ligament injuries. Clin Orthop Relat Res 198:43-49

146. Teodoro RL, Nishimi AY, Pascarelli L, Bongiovanni RR, Velasco MAP, Dobashi ET (2017) Surgical treatment of acromioclavicular dislocation using the endobutton. Acta Ortop Bras 25:81-84

147. Tiefenboeck TM, Boesmueller S, Popp D, Payr S, Joestl J, Binder H, Schurz M, Komjati M, Fialka C, Ostermann RC (2018) The use of the LARS system in the treatment of AC joint instabilitylong-term results after a mean of 7.4 years. Orthop Traumatol Surg Res 104:749-754

148. Torkaman A, Bagherifard A, Mokhatri T, Haghighi MHS, Monshizadeh S, Taraz H, Hasanvand A (2016) Double-button fixation system for management of acute acromioclavicular joint dislocation. Arch Bone Joint Surg 4:41-46

149. Triantafyllopoulos IK, Lampropoulou-Adamidou K, Schizas NP, Karadimas EV (2017) Surgical treatment of acute type V acromioclavicular joint dislocations in professional athletes: an anatomic ligament reconstruction with synthetic implant augmentation. J Shoulder Elbow Surg 26:e369-e375

150. Venjakob AJ, Salzmann GM, Gabel F, Buchmann S, Walz L, Spang JT, Vogt S, Imhoff AB (2013) Arthroscopically assisted 2-bundle anatomic reduction of acute acromioclavicular joint separations: 58-month findings. Am J Sports Med 41:615-621

151. Verdano MA, Pellegrini A, Zanelli M, Paterlini M, Ceccarelli F (2012) Modified Phemister procedure for the surgical treatment of Rockwood types III, IV, V acute acromioclavicular joint dislocation. Musculoskelet Surg 96:213-222

152. Verhaven E, DeBoeck H, Haentjens P, Handelberg F, Casteleyn PP, Opdecam P (1993) Surgical treatment of acute type-V acromioclavicular injuries in athletes. Arch Orthop Trauma Surg 112:189-192

153. Virtanen KJ, Remes VM, Tulikoura ITA, Pajarinen JT, Savolainen VT, Björkenheim J-MG, Paavola MP (2013) Surgical treatment of Rockwood grade- $\mathrm{V}$ acromioclavicular joint dislocations: 50 patients followed for 15-22 years. Acta Orthop 84:191-195

154. Vitali M, Pedretti A, Naim Rodriguez N, Franceschi A, Fraschini G (2015) Vascular graft employment in the surgical treatment of acute and chronic acromio-clavicular dislocation. Eur J Orthop Surg Traumatol 25:1205-1211

155. Vrgoč G, Japjec M, Jurina P, Gulan G, Janković S, Šebečić B, Starešinić M (2015) Operative treatment of acute acromioclavicular dislocations Rockwood III and V-Comparative study between K-wires combined with FiberTape( $(\circledR)$ vs. TightRope System(®). Injury 46(Suppl 6):S107-112
156. Vulliet P, Le Hanneur M, Cladiere V, Loriaut P, Boyer P (2018) A comparison between two double-button endoscopically assisted surgical techniques for the treatment acute acromioclavicular dislocations. Musculoskelet Surg 102:73-79

157. Walz L, Salzmann GM, Fabbro T, Eichhorn S, Imhoff AB (2008) The anatomic reconstruction of acromioclavicular joint dislocations using 2 TightRope devices: a biomechanical study. Am J Sports Med 36:2398-2406

158. Wang C, Huang S, Wang Y, Sun X, Zhu T, Li Q, Lin C (2015) Complete acromioclavicular joint dislocation treated with reconstructed ligament by trapezius muscle fascia and observation of fascial metaplasia. Open Med (Wars) 10:370-376

159. Wang C, Meng J-H, Zhang Y-W, Shi M-M (2020) Suture button versus hook plate for acute unstable acromioclavicular joint dislocation: a meta-analysis. Am J Sports Med 48:1023-1030

160. Wang G, Xie R, Mao T, Xing S (2018) Treatment of AC dislocation by reconstructing $\mathrm{CC}$ and $\mathrm{AC}$ ligaments with allogenic tendons compared with hook plates. J Orthop Surg 13:175

161. Wang S-J, Wong C-S (2008) Transacromial extra-articular Knowles pin fixation treatment of acute type $\mathrm{V}$ acromioclavicular joint injuries. J Trauma 65:424-429

162. Wang Y, Zhang J (2013) Surgical treatment of fresh complete acromioclavicular dislocation by coracoid process transfer and k-wire transfixation. Indian J Surg 75:436-439

163. Ware J, Kosinski M, Keller SD (1996) A 12-Item short-form health survey: construction of scales and preliminary tests of reliability and validity. Med Care 34:220-233

164. Ware JE, Sherbourne CD (1992) The MOS 36-item short-form health survey (SF-36). I. Conceptual framework and item selection. Med Care 30:473-483

165. Warren-Smith CD, Ward MW (1987) Operation for acromioclavicular dislocation. A review of 29 cases treated by one method. J Bone Joint Surg Br 69:715-718

166. Wei H-F, Chen Y-F, Zeng B-F, Zhang C-Q, Chai Y-M, Wang H-M, Lu Y (2011) Triple endobuttton technique for the treatment of acute complete acromioclavicular joint dislocations: preliminary results. Int Orthop 35:555-559

167. Weinstein DM, McCann PD, McIlveen SJ, Flatow EL, Bigliani LU (1995) Surgical treatment of complete acromioclavicular dislocations. Am J Sports Med 23:324-331

168. Williams GN, Gangel TJ, Arciero RA, Uhorchak JM, Taylor DC (1999) Comparison of the single assessment numeric evaluation method and two shoulder rating scales. Outcomes measures after shoulder surgery. Am J Sports Med 27:214-221

169. Wollmerstedt N, Kirschner S, Böhm D, Faller H, König A (2003) Design and evaluation of the extra short musculoskeletal function assessment questionnaire XSMFA-D. Z Orthop Ihre Grenzgeb 141:718-724

170. Xu J, Liu H, Lu W, Li D, Zhu W, Ouyang K, Wu B, Peng L, Wang D (2018) A retrospective comparative study of arthroscopic fixation in acute Rockwood type IV acromioclavicular joint dislocation: single versus double paired Endobutton technique. BMC Musculoskelet Disord 19:170

171. Xue C, Song L-J, Zhang H, Tang G-L, Li X, Fang J-H (2018) Truly anatomic coracoclavicular ligament reconstruction with 2 Endobutton devices for acute Rockwood type V acromioclavicular joint dislocations. J Shoulder Elbow Surg 27:e196-e202

172. Ye T, Ouyang Y, Chen A (2014) Multistrand titanium cable for the coracoclavicular stabilization of acute acromioclavicular joint dislocation. Acta Orthop Belg 80:178-182

173. Yin J, Yin Z, Gong G, Zhu C, Sun C, Liu X (2018) Comparison of hook plate with versus without double-tunnel coracoclavicular ligament reconstruction for repair of acute acromioclavicular joint dislocations: a prospective randomized controlled clinical trial. Int J Surg 54:18-23 
174. Yoo Y-S, Seo Y-J, Noh K-C, Patro BP, Kim D-Y (2011) Arthroscopically assisted anatomical coracoclavicular ligament reconstruction using tendon graft. Int Orthop 35:1025-1030

175. Yoon JP, Lee B-J, Nam SJ, Chung SW, Jeong W-J, Min W-K, Oh JH (2015) Comparison of results between hook plate fixation and ligament reconstruction for acute unstable acromioclavicular joint dislocation. Clin Orthop Relat Res 7:97-103

176. Zhao Y, Tan L, Tang W, Yu T (2019) A new coracoclavicular guider for minimally invasive anatomic coracoclavicular reconstruction with two TighTrope systems in acute acromioclavicular joint dislocation. Sci Rep 9:14452

177. Zheng J, Chen J, Chen L, Ni Y, Lin Z (2018) A novel hybrid fixation (coracoclavicular screw supplemented with K-wire) for the treatment of acute acromioclavicular joint dislocation: a prospective study. Int J Surg 59:61-66

Publisher's Note Springer Nature remains neutral with regard to jurisdictional claims in published maps and institutional affiliations.

\section{Affiliations}

\section{Maristella F. Saccomanno ${ }^{1}$ (D) Giuseppe Sircana ${ }^{1} \cdot$ Valentina Cardona $^{1} \cdot$ Valeria Vismara $^{1} \cdot$ Alessandra Scaini $^{2}$. Andrea G. Salvi ${ }^{2}$. Stefano Galli ${ }^{3}$. Giacomo Marchi ${ }^{3}$. Giuseppe Milano ${ }^{2,3}$}

Giuseppe Sircana
gsirca@hotmail.it

Valentina Cardona

valentina.cardona1819@gmail.com

Valeria Vismara

vale.vismara@gmail.com

Alessandra Scaini

alescaini@yahoo.it

Andrea G. Salvi

andreasalvi88@yahoo.it

Stefano Galli

elaste@libero.it
Giacomo Marchi

gmarchi73@gmail.com

Giuseppe Milano

giuseppe.milano@outlook.it

1 Orthopaedics Institute, Fondazione Policilinico A. Gemelli IRCCS, Largo A. Gemelli 8, 00168 Rome, Italy

2 University of Brescia, Brescia, Italy

3 Department of Bone and Joint Surgery, Spedali Civili, Brescia, Italy 